\title{
The concept of introduction and breeding of non-traditional vegetable plants in Siberia
}

\author{
Yury Fotev ${ }^{1,2^{*}}$, and Anna Artemyeva ${ }^{3}$ \\ ${ }^{1}$ Central Siberian Botanical Garden SB RAS, 630090 Novosibirsk, Russia \\ ${ }^{2}$ Novosibirsk State Agrarian University, 630039 Novosibirsk, Russia \\ ${ }^{3}$ N. I.Vavilov All-Russian Institute of Plant Genetic Resources, 190031 Saint-Petersburg, Russia
}

\begin{abstract}
The introduction of new vegetable crops in the harsh climate of Siberia presupposes the evaluation of resistance to environmental factors (long day, low temperatures, fungal diseases etc.) limiting the growth of plants, using pre-breeding methods. The studies were carried out in the outdoor and unheated plastic greenhouse conditions of the Central Siberian Botanical Garden (CSBS), Novosibirsk $\left(54^{\circ} \mathrm{N} 83^{\circ} \mathrm{E}\right)$ and in the outdoor and the conditions of phytotron of the N.I.Vavilov All-Russian Institute of Plant Genetic Resources (VIR). We used a large collection of species accessions belonging to families Leguminosae, Cucurbitaceae and Brassicaceae. It is proposed to use the taxonomically important, stable traits and other features that affect the possibility of scaling up the cultivation of crops in Siberia. Sequential assessment, e. g. asparagus bean includes evaluation of resistance to a long day, cold resistance in the phase of mature male gametophyte in vitro, the composition of pathogenic micromycetes, and the resistance of accessions to them. Also, it is offered to use the symbiotic systems, including the effective strains of Bradyrhizobium sp. and high-yield cultivars with a neutral response to day length and low variation in biochemical composition, for example, the cultivar 'Sibirskiy razmer' bred in the CSBS.
\end{abstract}

\section{Introduction}

Most botanists believe that introduction is the inclusion of plants into the cultivation practices of a country where they were previously absent [1]. The introduction of new vegetable crops in Siberia has its peculiar properties associated with a harsh climate and a short growing season with a sum of ten-degree temperatures of $1800-2000{ }^{\circ} \mathrm{C}$ [2]. At the same time favorable light conditions characterized by a significant number of hours of sunshine per year (1960-2100) and the amount of solar radiation of about $100 \mathrm{kcal} / \mathrm{cm}^{2} \mathrm{per}$ year [3], making it possible to successfully grow a wide range of vegetable plant species.

Methodological approaches based on parameters for obtaining a prognostic assessment of the effectiveness of the introduction of new vegetable crops in Siberia, also for the purposes involving the functional food, have been previously provided [4]. However, the breeding aspect of working with an introduced species is often relegated to the background

\footnotetext{
* Corresponding author: fotev_2009@mail.ru
} 
of ongoing research. With the aim of the future use of promising forms of a newly introduced species when creating cultivars for hi-tech agricultural production, it is necessary to solve several problems.1. It is necessary to isolate taxonomically important, stable features for the identification of intraspecific forms. 2. At the same time, it is necessary to isolate/select biological traits that limit the possibility of economically viable large-scale production.

\section{Materials and methods}

In the 2004-2020 research in open ground and plastic greenhouses of the Central Siberian Botanical Garden of the SB RAS (CSBS SB RAS), Novosibirsk $\left(54^{\circ} \mathrm{N} 83^{\circ} \mathrm{E}\right.$ ) based on the collection of N. I. Vavilov All-Russian Institute of Plant Genetic Resources (VIR), "Bioresource Scientific Collection of the Central Siberian Botanical Garden (CSBG SB RAS) UNU No.USU 440534 and under the phytotron conditions of VIR were carried out. The main species studied by the complex of characters in the CSBG SB RAS were asparagus bean (Vigna unguiculata (L.) Walp.), bitter melon (Momordica charantia L.), kiwano (Cucumis metuliferus E. Mey. ex Naudin), wax gourd (Benincasa hispida (Thunb.) Cogn.) and Chinese broccoli or kai-lan (Brassica oleracea L. var. alboglabra (Bailey) Musil.), in VIR: cabbage species Brassica oleraceae L., B. rapa L. The total number of used accessions is about 300. Morphometric and other features of plants were studied. Phenological observations were carried out in accordance with generally accepted recommendations. When describing the traits of asparagus bean, bitter melon, and wax gourd we used the recommendations of the State Commission of the Russian Federation for Selection Achievements Test and Protection [URL: http: //www.gossortrf.ru/mtd_dus.html]. Traditional methods of biochemical research of plants have been used.

\section{Results and discussion}

As a result of the study $V$. unguiculata, C. metuliferus, M. charantia, B. hispida and B. oleracea var. alboglabra accessions, taxonomically important, stable characters of these species characterizing seeds, leaves, stem and fruits for identification and grouping of intraspecific forms were selected, which is important for assessing future cultivars according to the criteria of distinctness, uniformity, and stability (DUS) (Table ).

Table. Taxonomically important, stable features of $V$. unguiculata, C. metuliferus, M. charantia, B. hispida, and B. oleracea var. alboglabra species for identification of intraspecific forms

\begin{tabular}{|c|c|}
\hline Feature & Feature characteristic \\
\hline \multicolumn{2}{|l|}{ V.unguiculata } \\
\hline Seeds: form & elliptical; reniform; curved \\
\hline Seeds: main color & $\begin{array}{l}\text { white; light yellow; brown; reddish-brown; violet brown; } \\
\text { black }\end{array}$ \\
\hline Seed: the presence of secondary color & absent; present \\
\hline Seed: secondary color & $\begin{array}{l}\text { yellow light *; brown; reddish-brown; violet brown; } \\
\text { black }\end{array}$ \\
\hline Stem: pigmentation of nodes $*$ & absent; present \\
\hline Fruit: anthocyanin color & absent; present \\
\hline Fruit: length & short; middle length; long \\
\hline \multicolumn{2}{|l|}{ C.metuliferus } \\
\hline
\end{tabular}




\begin{tabular}{|c|c|}
\hline Leaf blade: shape* & 3-blades; 5-blades \\
\hline Fruit: color* & $\begin{array}{l}\text { gray-green, uniform, without spotting; green spotted } \\
\text { around thorns }\end{array}$ \\
\hline Fruit: size* & middle; big \\
\hline \multicolumn{2}{|l|}{ M.charantia } \\
\hline $\begin{array}{l}\text { Seed: intensity of } \\
\text { the brown color of the testa }\end{array}$ & light; medium; dark \\
\hline Leaf-blade: number of lobes & five; seven; nine \\
\hline Pubescence of the tops of the shoots * & weak; medium; strong \\
\hline Fruit: length & short; middle length; long \\
\hline Fruit color of unripe fruit & white; light green; green; dark green \\
\hline Fruit: the number of tubercles & мало; среднее число; много \\
\hline Fruit: the presence of thorns & absent; present \\
\hline Fruit: интенсивность горечи & слабая; средняя; сильная \\
\hline \multicolumn{2}{|l|}{ B.hispida } \\
\hline Seeds: наличие ободка & absent; present \\
\hline Seeds: size & small; medium size; large \\
\hline Seeds: shape & narrow elliptical; elliptical; wide-elliptical \\
\hline Fruit: наличие воскового налета & absent; present \\
\hline Fruit (intensity of waxy bloom)* & weak; medium; strong \\
\hline $\begin{array}{l}\text { Fruit: intensity of the main green color } \\
\text { of the skin }\end{array}$ & light; medium; dark \\
\hline $\begin{array}{l}\text { Fruit: the presence of yellow-green } \\
\text { spots on the surface of the fruit } *\end{array}$ & absent; present \\
\hline Fruit: pubescence of fruit when ripe * & absent, medium; strong \\
\hline Fruit: weight & easy; average weight; heavy \\
\hline Fruit: shape & oval; cylindrical; cubiform \\
\hline Fruit: length & short; middle length; long \\
\hline Time of the onset of ripeness & early; medium; late \\
\hline \multicolumn{2}{|l|}{ B.oleraceae var. alboglabra } \\
\hline Leaf: intensity of green color * & light; medium; dark \\
\hline Presence of a leaf outgrowth $*$ & absent; present \\
\hline Color of flower petals $*$ & white; yellow \\
\hline
\end{tabular}

* additionally recommended for use by authors.

It is recommended to use additional stable features: the light yellow additional color of seeds and pigmentation of nodes when evaluating the forms of asparagus bean. We offer to use the shape of a leaf, as well as the size and color of fruit when describing the features of kiwano (the Russian descriptor of kiwano is not yet available). Also, when characterizing the traits of bitter melon, it is proposed to include to descriptor list the pubescence of the tops of the shoots.

The wax plaque formed on the surface of the wax gourd fruit is an inherited dominant multifactorial quantitative trait that varies widely from the complete absence of plaque $(0$ $\mathrm{mg}$ per fruit in the form 'Kunmingskaya' to its strong intensity $(1.13 \pm 0.23 \mathrm{~g} /$ fruit in the 'Akulina' cultivar).

The presence of a yellow-green spot on the surface of the fruit during harvesting is a 
recessive multifactorial quantitative trait that varies widely in different varieties and forms. The persistence of pubescence on the surface of the fruit at the time of their maturation is probably also a recessive trait with an insufficiently studied pattern of inheritance.

When describing the features of Chinese broccoli, the most significant traits are the intensity of the green color of the leaves, the presence of leaf outgrowth, and the color of the flower petals.

Based on the features characterizing the growth, development, shape, size, and color of plants and their parts, together with the State Commission of the Russian Federation for the Testing and Protection of Breeding Achievements, a national method for describing the traits of asparagus bean was developed [URL: https://gossortrf.ru/metodiki-ispytaniy-naoos/].

The ratio of the total number of registered cultivars by crop to the number of years since the year of inclusion in the State Register of the first cultivar shows the relative degree of demand for the crop, although this may also indicate the lack of available intraspecific genetic diversity (biodiversity) necessary for its breeding improvement. The calculated "coefficient of demand for the crop" turned out to be the maximum for asparagus bean (179), Chinese cabbage (107), and pakchoi, Brassica rapa L. (95).

The problem for the future expansion of production of cold-resistant crops used as greens (species from the Brassicaceae family) in specialized agricultural enterprises is more related to the lack of agricultural technologies and the supply of high-quality seed material, and to a lesser extent to biological features (e.g., sensitivity to photoperiod or resistance to pathogens) in comparison with non-traditional thermophilic vegetable crops. On the contrary, many introduced species of thermophilic warm $\square$ stenoterm taxa from the families Cucurbitaceae and Leguminosae with narrow ecological plasticity are carriers of biological traits that prevent the expansion of their growing in the regions of Russia (weak resistance to low temperatures and long photoperiod, susceptibility to certain diseases). The selected forms of these species require a comprehensive assessment and genetic improvement.

To accelerate the selection of initial material for cold-resistant crops, e.g., productive forms of species from the genus Brassica L., it is recommended to use genetic markers. For example, as a result of molecular screening of Chinese broccoli using 5 SSR markers (Na10D09, O112F02, Ra2E12, BC 7, and BC 65), genetically linked to some biochemical and morphological characters, the greatest polymorphism was in the test with the $\mathrm{BC} 7$ marker - five alleles from 160 to 295 bp in size [5]. The BC 7 marker is linked to loci that control leaf number and aphid resistance.

Additionally, some species carry undesirable organoleptic properties and therefore require additional breeding efforts. For example, kiwano has a large number of seeds in the fruit, however, inducing the parthenocarpy would help to solve this problem.

Using the example of the asparagus bean (Vigna unguiculata), it is possible to identify promising directions for its assessment and breeding as a new crop for Russia. The first Russian cultivars, 'Sibirskiy razmer' (Siberian size) and 'Yunnan'skaya', created in the SCBG have a neutral reaction to photoperiod and are distinguished by a high early maturity. For agricultural production in Siberia, it is recommended to use symbiotic systems based on the 'Sibirskiy razmer'and 'Yunnan'skaya' cultivars and the corresponding effective strains of nitrogen-fixing bacteria of the genus Bradyrhizobium sp. [6]. These systems showed the level of symbiotic fixation of $\mathrm{N}_{2}$ corresponding to the level of different cultivars of this crop in traditional areas of its production.

In the SCBG the twenty V.unguiculata accessions were screened for resistance to low temperature in the mature male gametophyte phase in vitro. The highest indices of cold resistance as the ratio of pollen germination in vitro on a $20 \%$ PEG6000 solution at a low temperature $\left(10^{\circ} \mathrm{C}-24 \mathrm{~h}\right)$ to the index at $25^{\circ} \mathrm{C}$ for $3 \mathrm{~h}$ were observed in samples: 'Lulin' (87\%), 'Zinder' (65\%) and 'Sibirskiy razmer' (46\%). 
An assessment of the pathogenic micromycetes composition of V.unguiculata in Siberia and the resistance of accessions to them was also carried out [7]. Specimens showing a high level of resistance to Botrytis cinerea Pers. and Sclerotinia sclerotiorum (Lib.) de Bary are form 901, form \# 323 ["striped"], 'Early Prolificacy Xiao Bao \# 2', F $F_{1}$ (Early Prolificacy Xiao Bao \# 2 x Sibirskiy razmer) and $F_{3}$ (Early Prolificacy Xiao Bao \# 2 x Sibirskiy razmer).

The results of cultivation of $V$. unguiculata cultivars in different regions of the country (in Crimea and the south of Western Siberia) showed that the highest homeostasis in the accumulation of macro-and microelements by seeds and, accordingly, the smallest variation (coefficient of variation, CV) is characteristic of the cultivar 'Sibirskiy razmer' (CV $=15$ $23 \%)$, macronutrients - the form Vigna catjang (Burm.f.) Walp. (CV $=14 \%)$ [8].

Thus, as a result of the research, a concept for the introduction and breeding of new vegetable crops for Siberia or other regions with harsh climate is proposed. The proposed concept is in line with a new direction of breeding, called "ecotyping" [9]. In the process of introduction, it is recommended to isolate taxonomically important, stable traits, as well as biological features of introduced species that affect the expansion of production of new crops, such as (along with productivity) response to day length, early maturity, resistance to low temperatures and diseases. As an example, the methodological approach to assessing resistance V.unguiculata to low temperatures includes the evaluation of cold resistance in the phase of mature male gametophyte in vitro on 20\% PEG6000 solution. For use in Siberia and other regions, it is recommended to use symbiotic systems, including effective strains of Bradyrhizobium sp. and high-yield cultivars of asparagus bean with neutral response to day length and low variation in biochemical composition (e.g., 'Sibirskiy razmer').

\section{References}

1. N. A. Bazilevskaya, Theory and methods of plant introduction (MGU, Moscow, 1964)

2. L. V. Voronina, A. G. Gritsenko, Climate and ecology of the Novosibirsk region (SGGA, Novosibirsk, 2011)

3. A. G. Krivonogova, Geography of the Novosibirsk region (Zapadno-Sibirskoe knizhnoe izdatelstvo, Novosibirsk, 1969)

4. Y. V. Fotev, Vestnik NGAU 14, 7 (2018)

5. Y. V. Fotev, A. M. Artemyeva, D. A. Fateev, N.B. Naumova, G. A. Bugrovskaya, V. P. Belousova, T. A. Kukushkina, Vegetable crops of Russia, 1 (2018)

6. Y. V. Fotev, K. K. Sidorova, T. I. Novikova, V. P. Belousova, Vavilov Journal of Genetics and Breeding, 20, 3 (2016)

7. Y. V. Fotev, O. A. Kazakova, BIO Web of Conferences 24 (2020)

8. Y.V. Fotev, O. M. Shevchuk, A. I. Syso, Chemistry of plant raw material, 2 (2021)

9. Z. Li-Xin, L. Wei, M. Tsegaw, X. Xin, Q. Yan-Ping, E. Sapey, L. Lu-Ping, W. TingTing, S. Shi, H. Tian-Fu, Journal of Integrative Agriculture, 19, 2 (2020) 